Review Article

\section{Gy single dose radiotherapy for bone metastasis in COVID-19 pandemia period: Review}

\section{Bora Uysal*, Hakan Gamsız, Ferrat Dincoglan, Omer Sager, Selcuk Demiral and Murat Beyzadeoglu}

Gulhane Medical Faculty, Department of Radiation Oncology, University of Health Sciences, Ankara, Turkey

\section{Abstract}

Bone metastases in cancer patients are highly painful and decrease the quality of life for these group of population. Covid-19 pandemia is a global challenging issue that mostly affect the patients with immune suppression or having comorbid diseases older than 65 years old. The palliation and management of bone metastases varies from single dose to several fractionation. The main goal of this article is to decide that short or long term fit for the cancer patients with bone metastasis in the Covid-19 era. We reviewed the topic about the short course and long term radiotherapy in the patients with painful bone metastases via novel literature.

\section{More Information}

*Address for Correspondence: Bora Uysal, Gulhane Medical Faculty, Department of Radiation Oncology, University of Health Sciences, Ankara, Turkey, Tel: +903123042000 ; Fax: +903123042000; Email: drborauysal@windowslive.com

Submitted: 21 April 2020

Approved: 05 May 2020

Published: 06 May 2020

How to cite this article: Uysal B, Gamsız H, Dincoglan F, Sager O, Demiral S, et al. 8 Gy single dose radiotherapy for bone metastasis in COVID-19 pandemia period: Review. J Radiol Oncol. 2020; 4: 005-007.

DOI: 10.29328/journal.jro.1001032

ORCiD: orcid.org/0000-0002-7288-7005

Copyright: @ 2020 Uysal B, et al. This is an open access article distributed under the Creative Commons Attribution License, which permits unrestricted use, distribution, and reproduction in any medium, provided the original work is properly cited.

Keywords: Single dose radiotherapy; COVID-19; Bone metastasis

Abbreviated title: 8 Gy radiotherapy for bone metastasis in pandemia

\section{Introduction}

The international pandemia of COVID-19 impacts all the people and also cancer patients, families and their healthcare providers worldwide. Staying home and social distancing as well as wearing a mask in case of going out in public for anything is recommended. Immune system of cancer patients is often weakened by cancer and the treatments such as chemotherapy and radiotherapy. Cancer patients are more vulnerable to infectious diseases in their treatment and follow-up periods.

Cancer patients and their caregivers should take precautions to decrease their risk of getting COVID-19. COVID-19 is a disease caused by a coronavirus which led to a large outbreak that firstly reported in China in December 2019. SARS-CoV-2 is the novel name of this coronavirus that spreads in an identical way to the common cold or to influenza. The majority of individuals who contact the novel coronavirus will experience mild to moderate symptoms but a smaller percentage who may be medically fragile will need medical attention and also possible hospitalization.

Aged 65 or older adults, people living in nursing homes or long-term care facilities or those who have weakened immune systems, chronic lung disease, serious heart conditions, obese, diabetic, kidney failure, or liver disease are the risky population for COVID-19 infection. Cancer and

\section{D) Check for updates \\ OPEn Access}

its treatment, smoking, having an organ transplant, poorly controlled HIV or AIDS and taking medicines such as steroids weaken the immune system [1].

\section{Discussion}

Bone metastases often originate from tumors such as prostate, breast, lung, thyroid, kidney cancers and melanoma. It effects the quality of life in cancer patients and cause intractable pain. Spine, pelvis and ribs are the most common sites of metastases in decreasing order [2]. Metastases of bone can be osteoblastic or osteolytic. Mechanical instability, irritation of periost, tumor-directed osteoclast-mediated osteolysis, tumor induced nerve injury and stimulation of cytokine receptors are the possible mechanisms of bone metastases [3]. Pain management include systemic treatment, surgery, radiotherapy and radiopharmeuticals. Nonopioid analgesics like acetaminophene, nonsteroidal anti-inflammatory drugs, codein, morphine, bisphosphonates and chemotherapy are the major systemic agents used for metastases. Surgery is often performed to prevent or treat pathological fractures [4]. 
Table 1: Comparison of single and multiple fractions used for bone metastasis in trials.

\begin{tabular}{|c|c|c|c|c|c|}
\hline & Number of patients & Dose (Gy) & Survival(median) & Complete response & Retreatment \\
\hline Nielsen 1998 & 241 & $8 / 1$ vs. $20 / 5$ & NA & 15 vs. 15 & 21 vs. 12 \\
\hline Koswig and Budach 1999 & 107 & $8 / 1$ vs. $30 / 10$ & NA & 33 vs. 31 & NA \\
\hline Bone Pain working party 1999 & 761 & $8 / 1$ vs. $20 / 5$ & NA & 57 vs. 58 & 23 vs. 10 \\
\hline Steenland 1999 & 1171 & $8 / 1$ vs. $20 / 5$ & 7 & 37 vs. 33 & 25 vs. 7 \\
\hline Kirkbride 2000 & 398 & $8 / 1$ vs. $20 / 5$ & NA & 22 vs. 29 & NA \\
\hline Hartsell 2005 & 949 & $8 / 1$ vs. $30 / 10$ & 9.1 vs. 9.3 & 15 vs. 18 & 18 vs. 9 \\
\hline Kaasa 2006 & 376 & $8 / 1$ vs. $30 / 10$ & 9.6 vs. 7.9 & NA & 16 vs. 4 \\
\hline Foro Arnalot 2008 & 160 & $8 / 1$ vs. $30 / 10$ & 6.5 vs. 7.6 & 15 vs. 13 & 2 vs. 28 \\
\hline
\end{tabular}

NA: Not available; vs.: versus; Gy: Gray

Radiotherapy is an effective management for palliating symptoms of bone metastases. $50 \%$ of patients were given full and $80 \%$ of patients were given partial relief in a study. The common fractionation varies from 30 Gy in 10 fractions, 20 Gy in 5 fractions, 8 Gy in 1 fraction [5].

No significant differences were determined between shorter or longer course of radiotherapy in randomized studies. Hoskin and Jeremic randomized patients to 4 Gy, 6 Gy or 8 Gy doses. Finally, 8 Gy arm was superior to 6 and 4 Gy because of the fact that threshold dose is necessary for achieving adeqaute palliation [6,7]. Overall or complete response rates were similar between groups of $8 \mathrm{~Gy}$ in single fraction and 24 Gy in 3 fractions in the Dutch study. Retreatment rates of single fraction radiotherapy was slightly higher than multipl fractions. Pathological fracture rates in treated area were similar between the groups according to this study [8]. 8 Gy in single fraction and $30 \mathrm{~Gy}$ in 10 fractions were analyzed in RTOG 9714 study [9]. The response rates including complete or partial pain relief were similar between groups. The patients delivered of $8 \mathrm{~Gy}$ were needed retreatment more than the patients managed with 30 Gy in 10 fractions in this study in line with Dutch experience.

The studies have some similar results about single and longer courses for bone metastases. Firstly, 8 Gy single dose provides pain relief similarly with longer treatments. Retreatment ratios are slightly higher for single fraction compared to longer courses. Response rates are much better when the initial pain scores are lower. There is no doseresponse relationship for palliation of bone metastases. The comparison of single and multiple fractions of radiotherapy in the treatment of bone metastasis is listed in the table (Table 1).

The role of stereotactic radiosurgery was analyzed in a study of RTOG 0631. 8 Gy single dose EBRT (external beam radiotherapy) and 16 Gy SRS (stereotactic radiosurgery) were comparatively evaluated. As a result of this study, the safety and feasibility of SRS was achieved [10]. Long term pain level improvement and tumor control were demonstrated in a group of patients treated with single dose radiosurgery in a study by University of Pittsburgh with 500 cases [11].

SABR (stereotacticablative bodyradiotherapy) is effective, feasible and well-tolerated therapy for oligometastatic bone only metastasis of breast cancer. 20 Gy single dose radiotherapy was delivered to the patients. Two third of patients were disease free for two years [12]. Evidence based research that comparing single dose radiotherapy and SBRT for the oligometastatic non-complex bone metastasis is needed for future recommendations [13]. SBRT can be used for the patients with oligometastatic disease, radiationresistant tumor and for reirradiation [14].

\section{Results}

This review is aimed to enlighten the affectivity and practicality of the single fraction of radiotherapy to prevent the cancer patients with bone metastases and the healthcare staff from COVID-19 infection. We highly recommend the radiation oncologists to use single dose radiotherapy either with EBRT or SRS in the COVID-19 pandemia era.

\section{References}

1. Latest news. Common questions about coronavirus outbreak. Cancer.

2. Nielsen OS, Munro AJ, Tannock IF. Bone metastases: pathophysiology and management policy. J Clin Oncol. 1991; 9: 509-524.

PubMed: https://www.ncbi.nlm.nih.gov/pubmed/1705581

3. Goblirsch MJ, Zvolak PP, Clohisy DR. Biology of bone cancer pain. Clin Cancer Res. 2006; 12: 6231-6235.

PubMed: https://www.ncbi.nlm.nih.gov/pubmed/17062706

4. Zech DF, Grond S, Lynch J, Hertel D, Lehmann KA. Validation of WHO guidelines for cancer pain relief: 10 year prospective study. Pain. 1995; 63: 65-76.

PubMed: https://www.ncbi.nlm.nih.gov/pubmed/8577492

5. Wu JS, Wong R, Johnston M, Bezjak A, Whelan T, et al. Metaanalysis of dose-fractionation radiotherapy trials fort he palliation of painful bone metastases. Int J Radiat Oncol Biol Phys. 2003; 55: 594605.

PubMed: https://www.ncbi.nlm.nih.gov/pubmed/12573746

6. Hoskin PJ, Price P, Easton D, Regan J, Austin D, et al. A prospective randomized trial of $4 \mathrm{~Gy}$ or $8 \mathrm{~Gy}$ single doses in the treatment of metastatic bone pain. Radiother Oncol. 1992; 23: 74-78. PubMed: https://www.ncbi.nlm.nih.gov/pubmed/1372126

7. Jeremic B, Shibamato $Y$, Acimovic L, Milicic B, Milisavljevic S, et al. A randomized trial of three single dose radition therapy regimens in the treatment of metstatic bone pain. Int J Radiat Oncol Biol Phys. 1998; 42: 161-167.

PubMed: https://www.ncbi.nlm.nih.gov/pubmed/9747834

8. Steenland E, Leer JW, van Houewelingen $\mathrm{H}$, Post WJ, van den Hout $W B$, et al. The effect of a single fraction compared to multiple fractions 
on painful bone metastases: a global analysis of the Dutch Bone metastases study. Radiother Oncol. 1999; 52: 101-109.

PubMed: https://www.ncbi.nlm.nih.gov/pubmed/10577695

9. Hartsell WF, Scott CB, Bruner DW, Scarantino CW, Ivker RA, et al. Randomized trial of short-versus long course radiotherapy for palliation of painful bone metastases. J Natl Cancer Inst. 2005; 97 : 798-804.

PubMed: https://www.ncbi.nlm.nih.gov/pubmed/15928300

10. Ryu S, Pugh SL, Gerszten PC, Yin FF, Timmerman RD, et al. RTOG 0631 Phase 2/3 study of image guided stereotactic radiosurgery for localized spine metastases: phase 2 results. Pract Radiat Oncol. 2014; 4: 76-81.

PubMed: https://www.ncbi.nlm.nih.gov/pubmed/24890347

11. Gertzen PC, Burton SA, Ozhasoglu C, Welch WC. Radiosurgery for spinal metastases: clinical experience of 500 cases from a single institution. Spine. 2007; 15: 193-199.

PubMed: https://www.ncbi.nlm.nih.gov/pubmed/17224814

12. Steven D, Jennifer T, Peter S, Bressel M, Kelly D, et al. Stereotactic ablative body radiotherapy (SABR) for bone only oligometastatic breast cancer: a prospective clinical trial. Breast. 2020; 49: 55-62. PubMed: https://www.ncbi.nlm.nih.gov/pubmed/31734589

13. Laila AG, Whitney HB, James AH, Mancini B, Jagsi R, et al. Recommendations for single-fraction radiation therapy and stereotactic body radiation therapy in palliative treatment of bone metastasis: a statewide practice patterns survey. Pract Radiat Oncol. 2019; 9: 541-548. PubMed: https://www.ncbi.nlm.nih.gov/pubmed/31326530

14. Shiloh R, Krishnan M. Radiation for treatment of painful bone metastasis. Hematol Oncol Clin North Am. 2018; 32: 459-468. PubMed: https://www.ncbi.nlm.nih.gov/pubmed/29729781 